\title{
A car-borne SAR and InSAR experiment
}

Frey, Othmar ; Werner, Charles L ; Wegmüller, Urs ; Wiesmann, Andreas ; Henke, Daniel ; Magnard, Christophe

\begin{abstract}
In this contribution, a car-borne SAR and InSAR experiment is described. The slope of a valley was imaged by means of a single-pass InSAR system mounted on a car driving on roads along the bottom of the valley. The GAMMA portable radar interferometer GPRI-II hardware with a modified antenna configuration was used for data acquisition. The experimental setup (1), SAR imagery focused along a slightly curved sensor trajectory (2), and first interferometric results (3) obtained using this configuration are presented.
\end{abstract}

DOI: https://doi.org/10.1109/IGARSS.2013.6721100

Posted at the Zurich Open Repository and Archive, University of Zurich

ZORA URL: https://doi.org/10.5167/uzh-92065

Conference or Workshop Item

Published Version

Originally published at:

Frey, Othmar; Werner, Charles L; Wegmüller, Urs; Wiesmann, Andreas; Henke, Daniel; Magnard, Christophe (2013). A car-borne SAR and InSAR experiment. In: Geoscience and Remote Sensing Symposium (IGARSS), 2013 IEEE International, Melbourne, Australia, 21 July 2013 - 26 July 2013. IEEE Xplore, 93-96.

DOI: https://doi.org/10.1109/IGARSS.2013.6721100 


\section{A CAR-BORNE SAR AND INSAR EXPERIMENT}

\author{
Othmar Frey \\ Gamma Remote Sensing / \\ Earth Observation \& \\ Remote Sensing, ETH Zurich \\ Switzerland \\ Email: frey@gamma-rs.ch
}

\author{
Charles L. Werner \\ Urs Wegmuller \\ Andreas Wiesmann \\ Gamma Remote Sensing \\ Switzerland
}

\author{
Daniel Henke \\ Christophe Magnard \\ Remote Sensing Laboratories \\ University of Zurich \\ Switzerland
}

\begin{abstract}
In this contribution, a car-borne SAR and InSAR experiment is described. The slope of a valley was imaged by means of a single-pass InSAR system mounted on a car driving on roads along the bottom of the valley. The GAMMA portable radar interferometer GPRIII hardware with a modified antenna configuration was used for data acquisition. The experimental setup (1), SAR imagery focused along a slightly curved sensor trajectory (2), and first interferometric results (3) obtained using this configuration are presented.

Index Terms-Synthetic aperture radar (SAR), groundbased SAR system, SAR imaging, SAR interferometry, carborne SAR, CARSAR
\end{abstract}

\section{INTRODUCTION}

Synthetic aperture radar interferometric techniques have been widely used to produce digital elevation models (DEMs) on a regional to global scale and to measure displacements in repeat-pass mode. Apart from spaceborne and airborne radars, also ground-based radar systems have appeared [1]-[4]. Ground-based radars add complementary advantages, such as timely in-situ measurements taken from a suitable viewpoint and repeatability of measurements in both time and space. They are therefore suitable to measure ground motion, to monitor land-slides, as well as to measure the topography of the illuminated area. In 2007, Gamma Remote Sensing developed a portable terrestrial real-aperture radar interferometer operating in the Ku-band at $17.2 \mathrm{GHz}$ [1], [5]. The one-transmit-dual-receive configuration allows for a simultaneous acquisition of two SAR data sets in a single pass. Therefore, an interferometric evaluation of the illuminated scene is possible including rapidly decorrelating targets such as a forest. In addition, the atmospheric phase contributions cancel out and there is potentially no need to separate motion from topography for repeat-pass measurements. For the experiment described here the GPRI-II radar was employed in a modified configuration to enable a synthetic aperture radar acquisition mode from an agile platform.

\section{EXPERIMENTAL SETUP}

In Fig. 1(a) the GPRI-II real-aperture terrestrial radar in its standard configuration is shown [2]. For the synthetic aperture radar experiment described here the following modifications were applied to the standard GPRI-II hardware:

1) The long real-aperture antennas were replaced by horn antennas to get a wider beamwidth which is suited for the synthetic aperture radar mode.

2) A different antenna rack was used such that the antennas can be mounted on the roof-top of a car.

3) Accurate positioning and basic attitude information was acquired by means of carrier-phase-based differential GPS measurements at an update rate of $20 \mathrm{~Hz}$.

Interferometric SAR data was acquired along two different roads (curved/straight) at different nearly constant velocities. The example data set presented in this contribution was taken from a slightly curved road at an average speed of $21 \mathrm{~m} / \mathrm{s}$. An overview of the system 


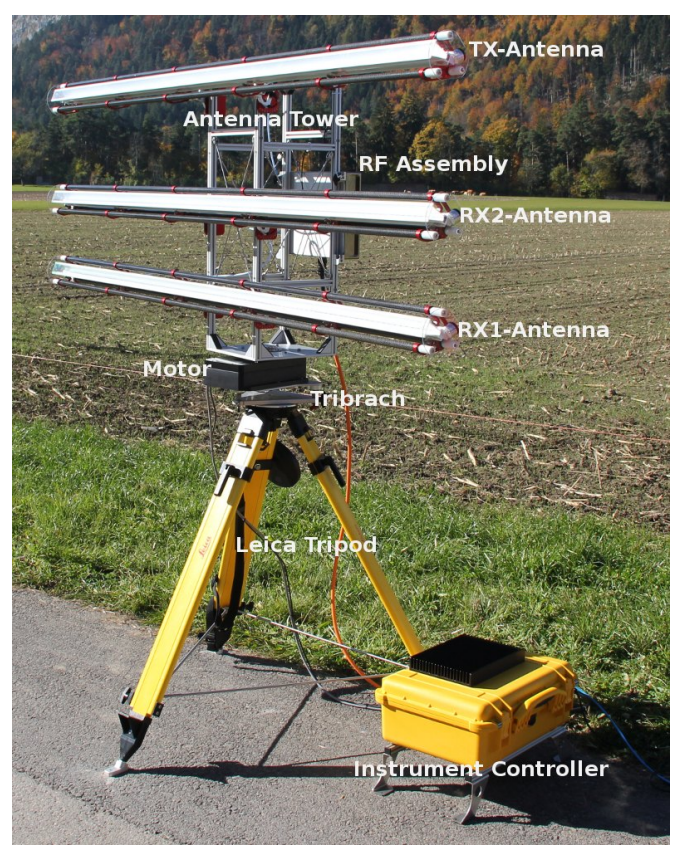

(a)

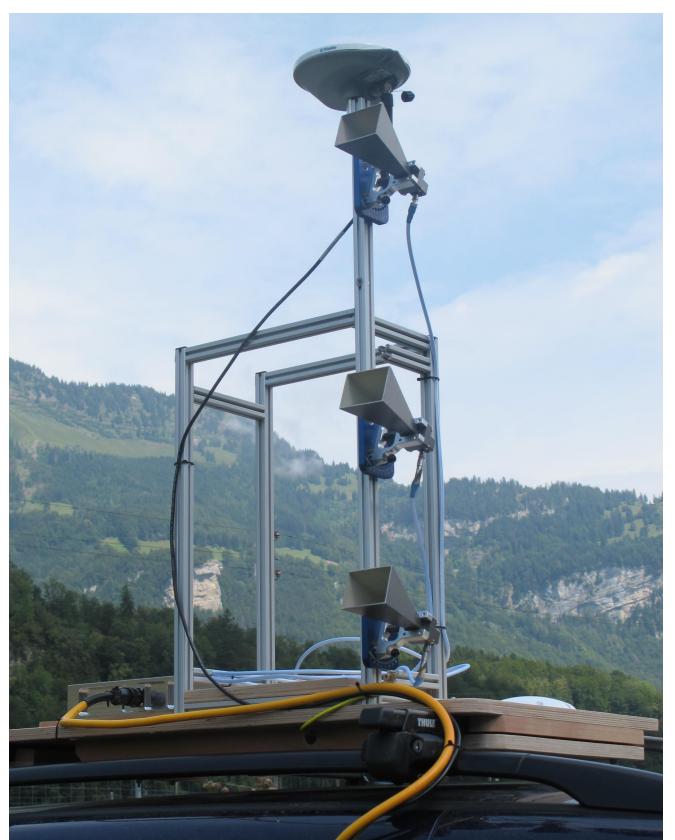

(b)

Fig. 1. (a) GPRI-II standard configuration (terrestrial real-aperture radar). (b) Modified antenna configuration and antenna rack including GPS antennas for accurate positioning as used in the CARSAR experiment.

TABLE I

GPRI-II GROUND BASED RADAR SYSTEM SPECIFICATIONS FOR SYNTHETIC APERTURE RADAR MODE.

\begin{tabular}{lc}
\hline \hline Carrier frequency & $17.2 \mathrm{GHz}$ \\
Chirp bandwidth & $200 \mathrm{MHz}$ \\
Type & FMCW \\
Chirp length & $0.001 \mathrm{~s}$ \\
Range 3dB beamwidth & $18 \mathrm{deg}$ \\
Azimuth 3dB beamwidth & $16.9 \mathrm{deg}$ \\
Ground speed & $21 \mathrm{~m} / \mathrm{s}$ \\
\hline Interferometric baseline & $0.25 \mathrm{~m}$ \\
Off-nadir angle & $110 \mathrm{deg}$ \\
\hline \hline
\end{tabular}

parameters for this configuration is given in Table I. Fig. 1(b) shows the modified radar system along with the GPS antennas as mounted on the roof-top of a car during their the synthetic aperture radar experiment.

\section{Processing Methods}

The linear FMCW-type GPRI-II radar works in dechirp-on-receive mode, thus the received signal $s(t)$ is mixed with the reference signal. This transforms the data to a deramped signal $s_{d}$ of the form [6]:

$$
s_{d}(t)=s^{*}(t) \exp \left(j 2 \pi f_{s} t+j \pi \gamma t^{2}\right),
$$

where $f_{s}$ is the start frequency of the chirp and $\gamma$ is the chirp rate. The phase of the resulting deramped signal is

$$
\varphi_{d}(t)=\left(2 \pi f_{s} t_{n}-\pi \gamma t_{n}^{2}\right)+2 \pi \gamma t_{n} t,
$$

which can be directly related to range distance via a range-Fourier transform. $t_{n}$ is the two-way time delay to a target $n$. In contrast to the matched-filter-based range imaging, a range-dependent quadratic phase error (within brackets), known as the residual video phase, remains after this range-compression operation [7]. While for static operation mode-which is the original purpose of the GPRI-II radar-this residual video phase can be neglected it has to be compensated if substantial rangecell migration occurs in the synthetic aperture operation mode.

SAR focusing along the slightly curved sensor trajectory following a main road was performed using a 


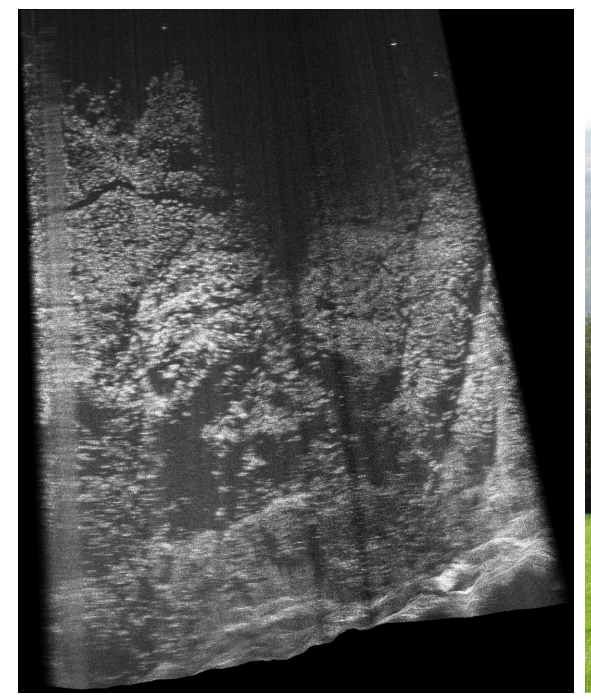

(a)

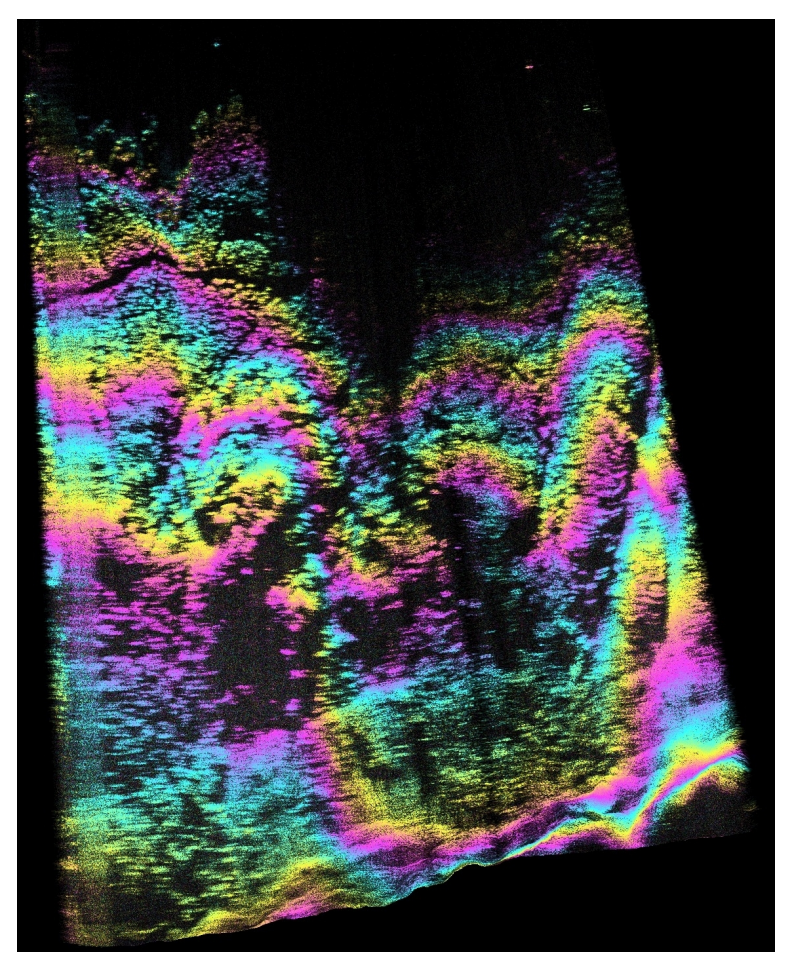

(c)

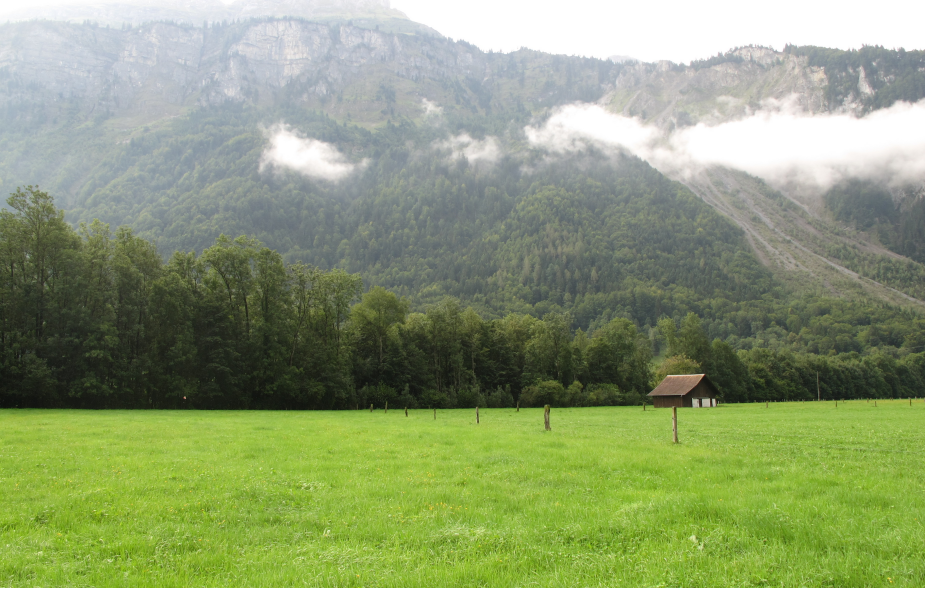

(b)

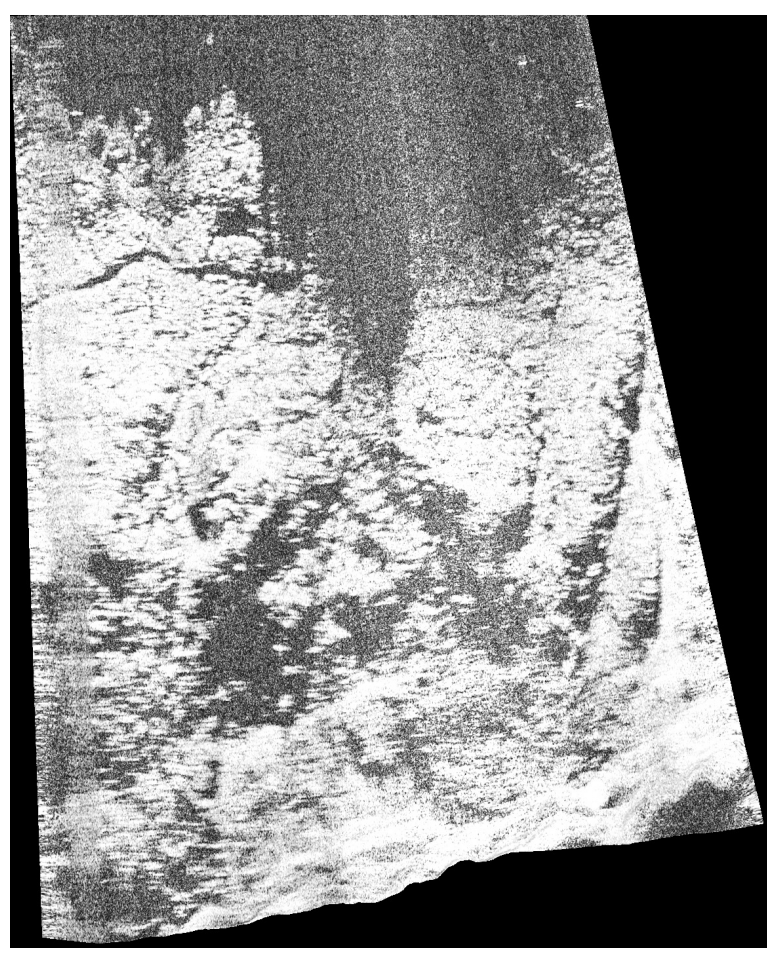

(d)

Fig. 2. Example SAR imagery of a slope of a valley taken from the car-borne interferometric SAR system: (a) SAR intensity image, (b) photograph of the imaged slope of the valley, (c) interferogram (blended with intensity image), (d) coherence magnitude.

time-domain back-projection processing approach [8]. Accurate positioning information was obtained by postprocessing of carrier-phase-based short-baseline differential GPS data relative to a GPS ad-hoc reference sta- tion that was set up on the test site. Due to the long chirp duration of 1 millisecond the start-stop approximation is not valid and therefore the time varying position of the sensor has to be taken into account during back- 
projection processing. A detailed treatment of this aspect is found in [9]).

\section{RESUlts}

In Fig. 2(a) a focused SAR image taken from the interferometric radar mounted on the roof-top of a car driving along a slightly curved highway is shown. Fig. 2(b) shows a photograph of the valley slope imaged by the car-borne SAR system. Figures 2(c) and 2(d) depict the single-pass interferogram and the coherence magnitude, respectively.

\section{CONCLUSION}

A CARSAR experiment using a modified configuration of the Ku-band FMCW GPRI-II terrestrial radar mounted on the roof-top of a car was described. First results of the campaign were presented including focused SAR imagery as well as single-pass interferometry from a slightly curved sensor along a highway demonstrating SAR imaging and single-pass SAR interferometry from an agile car-borne radar system. The SAR and InSAR data takes acquired within this experiment, which includes single-pass and repeat-pass data takes, are being used as a testbed for development and testing of SAR focusing and motion-compensation algorithms and also to evaluate interferometric SAR applications.

\section{REFERENCES}

[1] C. Werner, T. Strozzi, A. Wiesmann, and U. Wegmuller, "A realaperture radar for ground-based differential interferometry," in Proc. IEEE Int. Geosci. Remote Sens. Symp., vol. 3, July 2008, pp. 210-213.

[2] C. Werner, A. Wiesmann, T. Strozzi, A. Kos, R. Caduff, and U. Wegmuller, "The GPRI multi-mode differential interferometric radar for ground-based observations," in Proc. EUSAR 2012 - 9th European Conference on Synthetic Aperture Radar, Apr. 2012, pp. 304-307.

[3] G. Luzi, M. Pieraccini, D. Mecatti, L. Noferini, G. Guidi, F. Moia, and C. Atzeni, "Ground-based radar interferometry for landslides monitoring: atmospheric and instrumental decorrelation sources on experimental data," IEEE Transactions on Geoscience and Remote Sensing, vol. 42, no. 11, pp. 2454-2466, Nov. 2004.
[4] D. Leva, G. Nico, D. Tarchi, J. Fortuny-Guasch, and A. Sieber, "Temporal analysis of a landslide by means of a ground-based SAR interferometer," IEEE Transactions on Geoscience and Remote Sensing, vol. 41, no. 4, pp. 745-752, Apr. 2003.

[5] T. Strozzi, C. Werner, A. Wiesmann, and U. Wegmuller, "Topography mapping with a portable real-aperture radar interferometer," IEEE Geosci. Remote Sens. Lett., vol. 9, no. 2, pp. 277-281, Mar. 2012.

[6] M. Soumekh, Synthetic Aperture Radar Signal Processing: with MATLAB Algorithms. John Wiley \& Sons, 1999.

[7] W. G. Carrara, R. S. Goodman, and R. M. Majewski, Spotlight Synthetic Aperture Radar: Signal Processing Algorithms. Artech House Inc., 1995.

[8] O. Frey, C. Magnard, M. Rüegg, and E. Meier, "Focusing of airborne synthetic aperture radar data from highly nonlinear flight tracks," IEEE Trans. Geosci. Remote Sens., vol. 47, no. 6, pp. 1844-1858, June 2009.

[9] A. Ribalta, "Time-domain reconstruction algorithms for fmcwsar," IEEE Geoscience and Remote Sensing Letters, vol. 8, no. 3, pp. 396-400, May 2011. 